Objectives: 1) To assess BL clinical Disease Activity for Psoriatic Arthritis (cDAPSA) levels associated with achieving cDAPSA LDA or REM at Week 52 (Wk52); 2) predict cDAPSA response categories at Wk52 based on BL or Wk16 CDAPSA; 3 ) assess disease activity in different PsA domains associated with cDAPSA categories at Wk52.

Methods: Pooled analyses (PALACE 1-3) were performed of pts assigned to receive APR $30 \mathrm{mg}$ BID (APR30) at BL who completed Wk52 and had CDAPSA components available to calculate responses. Pts were grouped according to the CDAPSA categories reached at Wk52 (REM $\leq 4$; LDA $>4-\leq 13$; MDA $>13-\leq 27$; $H D A$ >27). Shifts of cDAPSA response categories from BL, Wk 16 to Wk52 were reported and provided the predictability of $B L$ status or early response to the achievement of cDAPSA categories at Wk52. Mean disease activity in core PsA domains, including swollen (0-76)/tender joint (0-78) (SJ/TJ), enthesitis (MASES), dactylitis count, Patient Global Assessment of Disease Activity (PtGA), Patient Assessment of Pain (PAP), Psoriasis Activity Severity Index (PASI), and Physical Function (HAQ) were reported longitudinally, allocated by cDAPSA category at Wk52. To better describe predictors associated with pts potentially being considered for APR in routine clinical practice, analyses were repeated removing pts in HDA at BL.

Results: 374 APR30 pts were included in the analyses. Pts who achieved MDA, LDA or REM at Wk52 indicated sustained improvements in cDAPSA over time; Means of BL cDAPSA scores $\leq 41$ were associated with achievement of MDA, LDA and REM at Wk52 (figure 1). At BL, pts in HDA had $42 \%, 24 \%$ and $5 \%$ chances of achieving MDA, LDA or REM at Wk52, respectively. Pts in MDA at BL had $41 \%$ and $12 \%$ chances of achieving LDA or REM. Pts in LDA had $20 \%$ chances of achieving REM. At Wk16, pts in HDA had $43 \%, 8 \%$ and $1 \%$ chances of achieving MDA, LDA or REM. Pts in MDA had $38 \%$ and $2 \%$ chances of achieving LDA or REM. Pts in LDA at BL had a $20 \%$ chance of achieving REM and pts in REM a $67 \%$ chance of staying in REM. Achieving cDAPSA LDA or REM with APR at Wk52 was associated with residual disease activity as follows: SJ (1.2 vs. 0.24$)$; TJ (2.6 vs. 0.52 ); MASES (1.2 vs. 0.43 ); dactylitis (0.47 vs. 0 ); PtGA (28.0 vs. 7.7 ); PAP (25.1 vs 7.2); PASI (4.0 vs. 2.7); HAQ (0.62 vs. 0.14 ). Removing pts with HDA at BL suggested that a mean CDAPSA 21 was associated with achieving LDA or REM at Wk52, corresponding to 5.5 in mean SJC and 9 in mean TJC at $\mathrm{BL}$

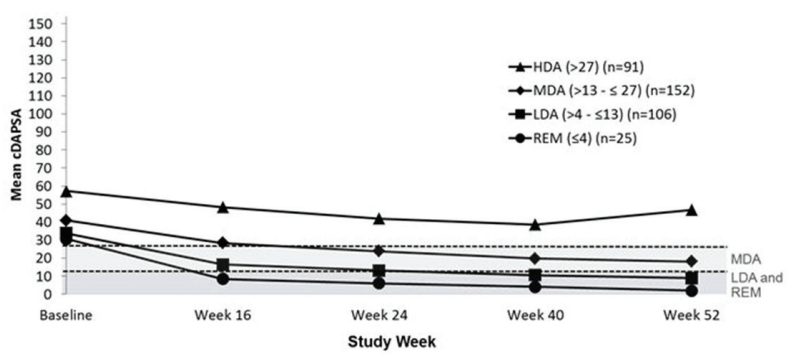

Abstract AB0927 - Figure 1

Conclusions: Chances of achieving LDA or REM were greater for pts in MDA at BL or Wk16 vs. HDA. Achieving LDA or REM at Wk52 with APR was associated with good outcomes across core PsA domains. Results suggest that pts with $B L$ moderate cDAPSA disease activity may be particularly suitable for APR therapy. Disclosure of Interest: I. McInnes Grant/research support from: Celgene, Abbvie, Pfizer, BMS, UCB, Roche, Janssen, P. Mease Grant/research support from: Abbott, Amgen, Biogen Idec, BMS, Celgene Corporation, Genentech, Janssen, Eli Lilly, Novartis, Pfizer, Roche, UCB, Consultant for: Abbott, Amgen, Biogen Idec, BMS, Celgene Corporation, Genentech, Janssen, Eli Lilly, Novartis, Pfizer, Roche, UCB, Speakers bureau: Abbott, Amgen, Biogen Idec, BMS, Genentech, Janssen, Eli Lilly, Pfizer, UCB, F. Behrens: None declared, A.-M. Orbai: None declared, M. Brunori Employee of: Celgene Corporation, L. Teng Employee of: Celgene Corporation, B. Guerette Employee of: Celgene Corporation, J. Smolen Grant/research support from: Abbvie, Janssen, Lilly, MSD, Pfizer, Roche, Speakers bureau: Abbvie, Amgen, Astra-Zeneca, Astro, Celgene Corporation, Celtrion, Glaxo, ILTOO, Janssen, Lilly, Medimmune, MSD, Novartis-Sandoz, Pfizer, Roche, Samsung, Sanofi, UCB

DOI: 10.1136/annrheumdis-2018-eular.5995

\section{AB0928 USTEKINUMAB AND TNF INHIBITORS IN PSORIATIC ARTHRITIS: FIRST FOLLOW-UP DATA FROM A ROUTINE CARE STUDY IN 8 EUROPEAN COUNTRIES (PSABIO)}

J.S. Smolen ${ }^{1}$, P. Bergmans ${ }^{2}$, I. Bondareva ${ }^{3}$, K. de Vlam ${ }^{4}$, E. Gremese ${ }^{5}$, B. Jovenlbáñez $^{6}$, T.V. Korotaeva ${ }^{7}$, M.T. Nurmohamed ${ }^{8}$, P.P. Sfikakis ${ }^{9}$, S. Siebert ${ }^{10}$, P. Smirnov ${ }^{11}$, E. Theander ${ }^{12}$, V. D'Abrosca ${ }^{13}$, L. Gossec ${ }^{14} .{ }^{1}$ Medical University of Vienna, Vienna, Austria; ${ }^{2} J a n s s e n-C i l a g$ B.V., Breda, Netherlands; ${ }^{3}$ Kemerovo Regional Clinical Hospital, Ministry of Health of Russia, Kemerovo, Russian Federation; ${ }^{4}$ University Hospitals Leuven, Leuven, Belgium; ${ }^{5}$ Fondazione Policlinico Gemelli-Catholic University of the Sacred Heart, Rome, Italy; ${ }^{6}$ University Hospital 12 de Octubre, Madrid, Spain; ${ }^{7}$ V.A. Nasonova Research Institute of Rheumatology, Moscow, Russian Federation; ${ }^{8}$ Amsterdam Rheumatology and Immunology Center, VU University Medical Centre and Reade, Amsterdam, Netherlands; ${ }^{9}$ University of Athens Medical School, Athens, Greece; ${ }^{10}$ University of Glasgow, UK; ${ }^{11}$ Janssen Pharmaceutica NV, Moscow, Russian Federation;

${ }^{12}$ Janssen EMEA, Issy-les-Moulineaux, France; ${ }^{13}$ Università della Campania "Luigi Vanvitelli", Naples, Italy, ${ }^{14}$ Sorbonne Université, Paris, France

Background: The purpose of PsABio (ClinicalTrials.gov Id: NCT02627768) is to evaluate the efficacy, tolerability and persistence of TNF inhibitors (TNFi) and ustekinumab (UST) for patients with psoriatic arthritis (PsA) starting 1st, 2nd or 3 rd line biologic disease-modifying antirheumatic drugs (bDMARDs) in real-world routine care.

Objectives: Here we present the first interim follow-up data on joint-related outcomes.

Methods: Of 278 UST- and 285 TNFi-treated patients consecutively enrolled between ${ }^{\text {Dec } 2015}$ and, Aug 2017152 and 151, respectively, had data available at 6 months for their initial line of treatment. Joint-related outcomes, as observed data, were compared between baseline and 6 months within the treatment cohorts.

Results: Among all enrolled patients, $7.6 \%$ of UST- and $10.2 \%$ of TNFi-treated patients stopped or switched to another bDMARD before the 6 month timepoint For those with 6 month data for their initial bDMARD, UST was used as the firstline bDMARD in $40.1 \%$, as 2 nd in $35.5 \%$, and as 3 rd in $24.3 \%$ of patients; these numbers were $64.2 \%, 28.5 \%$, and $7.3 \%$, respectively, for TNFi. DAS28 scores improved significantly at 6 months from mean baseline values of 4.3 (SD 1.2) and 4.3 (SD 1.2) for UST and TNFi, respectively, by means of $-1.3(95 \% \mathrm{Cl}:-1.6$, $-1.0)$ and $-1.3(95 \% \mathrm{Cl}:-1.6,-1.1)$. Significant improvements were seen in both cohorts across all treatment lines (table 1) and subtypes of PsA (data not shown). Minimal disease activity (MDA) was achieved at 6 months for $28.8 \%$ of UST- and $29.7 \%$ of TNFi-treated patients. CDAl results similarly and significantly improved. For the DAPSA, equally, statistically significant improvements were seen: mean $-18.4(95 \% \mathrm{Cl}:-22.2,-14.5)$ and $-19.5(95 \% \mathrm{Cl}:-22.5,-16.5)$ for UST and TNFi, respectively, with $12.2 \%$ and $15.7 \%$ reaching DAPSA remission and $37.8 \%$ and $37.1 \%$ reaching low disease activity. CDAPSA showed similar improvement. For details on components of the DAS28 and of the DAPSA, see table 1. Axial joint involvement was significantly improved with reductions in BASDAI and ASDAS.

Abstract AB0928 - Table 1. Baseline and follow-up data for joint-related outcomes for patients having reached 6 months on their initial bDMARD. Values are mean (SD) or mean $(95 \% \mathrm{Cl})$ if not otherwise indicated. na, not applicable.

\begin{tabular}{|c|c|c|c|c|}
\hline & $\begin{array}{c}\begin{array}{c}\text { Baseline UST } \\
(n=152)\end{array} \\
\text { (a) }\end{array}$ & $\begin{array}{l}\text { Change UST } \\
6 \text { months }\end{array}$ & $\begin{array}{c}\text { Baseline TNFi } \\
(n=151)\end{array}$ & $\begin{array}{l}\text { Change TNF } \\
6 \text { months }\end{array}$ \\
\hline Age, yrs & & & & \\
\hline $\begin{array}{l}\text { Diseasese duration sinces } \\
\text { diggnosis, yrs }\end{array}$ & $7.7(7.6)$ & na & $6.7(7.4)$ & na \\
\hline Sex (male). \% & 47.8 & na & 51.2 & na \\
\hline $\begin{array}{l}\text { Smoking, \%, ever } \\
\text { current } \\
\text { never }\end{array}$ & & na & & na \\
\hline & & & & \\
\hline $\begin{array}{l}\text { Weight }(\mathrm{kg}) \\
\text { BMI }\left(\mathrm{kg}_{\mathrm{g}} \mathrm{m}^{2}\right)\end{array}$ & $\frac{82.3(16.9)}{28.2(5.5)}$ & & $\begin{array}{c}80.4(15.2) \\
27.9(5.0)\end{array}$ & $\begin{array}{l}0.7(0.2,1.2) \\
0.2(0.1,0.4)\end{array}$ \\
\hline DAS28 & & & $4.3(1.2)$ & $-1.3(-1.6,-1.1)$ \\
\hline 1stline & $(n=61) 4.1(1.1)$ & $-1.0(-1.3,-0.6)$ & $(n=97) 4.1(1.3)$ & $-1.3(-1.6,-1.1)$ \\
\hline Z2nd line & $(n=91) 4.5(1.3)$ & $-1.5(-1.9,-1.1)$ & $(n=54) 4.6(1.2)$ & $-1.4(-1.7,-1.0)$ \\
\hline CDAI & $22.8(12.2)$ & $-10.9(-13.1,-8.6)$ & $21.8(12.2)$ & $-10.8(-12.6,-9.0)$ \\
\hline 1stline & $(n=48) 21.6$ (11.3) & $-10.2(-13.2,-7.1)$ & $(n=76) 20.4$ (11.7) & $-10.0(-12.2,-7.9)$ \\
\hline 22nd line & $n=73) 23.6(12.7)$ & $-11.3(-14.4,-8.2)$ & $(n=40) 24.4(12.9)$ & $-12.2(-15.4,-9.1)$ \\
\hline DAPSA & $34.7(21.2)$ & $-18.4(-22.2,-14.5)$ & 35.4 (19.1) & $-19.5(-22.5,-16.5)$ \\
\hline 1st line & $n=32) 32.2(15.3)$ & $-16.2(-21.3,-11.1)$ & $(n=56) 32.7(18.2)$ & $-17.8(-21.6,-13.9)$ \\
\hline 22nd line & $(n=50) 36.2(24.3)$ & $-19.7(-25.3,-14.2)$ & $(n=33) 40.0(20.1)$ & $-22.5(-27.3,-17.7)$ \\
\hline ¿DAPSA & 31.61 & $-15.6(-18.6,-12.5)$ & $32.2(19.1)$ & $-16.9(-19.4,-14.4)$ \\
\hline Swollen Jo & & $-2.7(-3.4,-1.9)$ & $4.0(4.5)$ & $-2.5(-3.1,-1.9)$ \\
\hline Swollen Joint Count & $6.4(8$ & $-4.3(-5.4,-3.2)$ & $7.0(7.1)$ & $-4.5(-5.4 .-3.6)$ \\
\hline Tender Joint & 7.56 & $-3.6(-4.8,-2.4)$ & 6.316 & $-3.1(-4.0,-2.3)$ \\
\hline Tender Joli & 13.0( & $-6.4(-8.4,-4.4)$ & $12.8(10.9)$ & $-6.7(-8.1,-5.3)$ \\
\hline Patient p & 58.96 & $-21.2(-26,0,-16,4)$ & $.5(23.7)$ & $-27.8(-32,3,-23,3)$ \\
\hline Patent g & 60.5( & $-23.1(-27.7,-18.4)$ & 60.2 & $-27.8(-32.3,-23.2)$ \\
\hline Physiciar & $55.3(18.4)$ & $-25.1(-29.0,-21.2)$ & $55.0(20$. & $-25.1(-2)$ \\
\hline (n) & $0.7(0.3$, & & $0.7(0.3$, & \\
\hline & & & & \\
\hline & & $1.2,-0.7)$ & & \\
\hline
\end{tabular}

${ }^{a}$ Among all patients with available data at baseline and month 6 (UST, $n=128$; TNFi, $n=114$ ).

${ }^{\mathrm{b}}$ Among all patients with available data at baseline and month 6 (UST, $\mathrm{n}=82$; TNFi, $n=87$ ).

Conclusions: Both UST- and TNFi-treated patients showed statistically significant and considerable improvements in joint-related measures after 6 months in a real-world setting, irrespective of whether first or further line of treatment. 
Acknowledgements: This study was sponsored by Janssen.

Disclosure of Interest: J. Smolen Grant/research support from: Received grants for his institution from AbbVie, Janssen, Lilly, MSD, Pfizer, and Roche, Speakers bureau: Provided expert advice to and/or had speaking engagements with AbbVie, Amgen, Astra-Zeneca, Astro, Celgene, Celtrion, GlaxoSmithKline, ILTOO, Janssen, Lilly, Medimmune, MSD, Novartis-Sandoz, Pfizer, Roche, Samsung, Sanofi, and UCB, P. Bergmans Shareholder of: Johnson and Johnson, Employee of: Janssen, I. Bondareva Grant/research support from: Served as investigator for clinical trials sponsored by Pfizer, Janssen, Biocad, K. de Vlam Consultant for: Johnson and Johnson, E. Gremese Consultant for: AbbVie, Janssen, Lilly, Pfizer, Speakers bureau: AbbVie, Janssen, Lilly, Pfizer, B. Joven-Ibáñez Speakers bureau: Celgene, Novartis, MSD, Pfizer, AbbVie, and Janssen, T. Korotaeva Consultant for: Pfizer, MSD, Novartis, AbbVie, Celgene, Biocad, Janssen, and UCB, Speakers bureau: Pfizer, MSD, Novartis, AbbVie, Celgene, Biocad, Janssen, and UCB, M. Nurmohamed Grant/research support from: Received research support to his institution from Pfizer, AbbVie, Roche, BMS, MSD, Mundipharma, UCB, Janssen, Menarini, Eli Lilly, Sanofi, and Celgene, Consultant for: Pfizer, AbbVie, Roche, BMS, MSD, Mundipharma, UCB, Janssen, Menarini, Eli Lilly, Sanofi, and Celgene, Speakers bureau: Pfizer, AbbVie, Roche, BMS, MSD, Mundipharma, UCB, Janssen, Menarini, Eli Lilly, Sanofi, and Celgene, P. Sfikakis: None declared, S. Siebert Grant/research support from: Receipt of grants/research support to his institution from Pfizer, Janssen, BMS, Celgene, UCB, and Boehringer Ingelheim. participation in clinical trials with AbbVie, Novartis, and UCB, Consultant for: AbbVie, UCB, Pfizer, Janssen, Boehringer Ingelheim, Celgene, and Novartis, Speakers bureau: AbbVie, UCB, Pfizer, Janssen, Boehringer Ingelheim, Celgene, and Novartis, P. Smirnov Employee of: Janssen, E. Theander Employee of: Janssen, V. D'Abrosca: None declared, L. Gossec Grant/research support from: Received grants for her institution from Pfizer, Consultant for: Received honoraria from AbbVie, Celgene, Janssen, Lilly, Novartis-Sandoz, Pfizer, Sanofi, and UCB

DOI: 10.1136/annrheumdis-2018-eular.6939

\section{AB0929 BURDEN OF SKIN AND JOINT SYMPTOMS OF PSORIATIC DISEASE: RESULTS OF A MULTI-NATIONAL PATIENT SURVEY}

J.F. Merola ${ }^{1}$, D. Shrom², J. Eaton ${ }^{2}$, C. Dworkin ${ }^{3}$, C. Kresbach ${ }^{3}$, B. Shah-Manek ${ }^{3}$ J. Birt ${ }^{2} .{ }^{1}$ Brigham and Women's Hospital, Boston; ${ }^{2}$ Eli Lilly and $\mathrm{Co}^{3}{ }^{3}$ psos Healthcare, Indianapolis, USA

Background: Psoriatic Arthritis (PsA) and Psoriasis (PsO), have a significant impact on health-related quality of life and work productivity loss. In patients with both PsA and $\mathrm{PsO}$, the full extent of the physical and emotional burden due to either joint related or skin related symptoms is not well understood from the perspective of the patient.

Objectives: To evaluate the patients' perspective on the overall burden of skin and joint related symptoms of PsA in a cross-sectional online survey.

Methods: A 20 min web based survey was developed based on analysis of 1-on1 interviews with 30 PsA patients from the US, France and Germany. The final survey contained validated instruments including the PSA Quality of Life (PSAQoL) and Work Productivity and Activity Impairment (WPAI) questionnaires as well as custom questions designed to capture emotional burden of PsA and its impact on daily activities/situations. Additional data collected included demographics, severity of $\mathrm{PsO}$ by patient-reported body surface area involvement (BSA), severity of PsA by RAPID3, impact of PsO and PsA by a Patient Global Assessment scale with focus on skin or joint symptoms. In total, 439 psoriatic arthritis (PsA) patients from the US (68\%), Germany (20\%) and France (12\%) were recruited to complete the survey.

Results: Among all participants, $30 \%$ had mild and $70 \%$ had mod-severe PsA based on RAPID-3 cutoffs, while $51 \%$ had mild and $48 \%$ had mod-severe PsO based on BSA cutoffs. According to multiple regression analyses, severity of joint symptoms and skin symptoms were signifcantly associated with lower PsAQoL $(p<0.0001)$ as was age $(p<0.0001)$. In patients with mild joint severity, impact of skin symptoms was significantly associated with PsAQoL $(p<0.0001)$ as well as age and gender $(p<0.05)$. Joint severity and impact of joint symptoms were the strongest contributors to the WPAI scores $(p<0.05)$. When asked to select the 2 emotions most associated with the impact of their joint symptoms, patients most often chose fatigue (36\%), worry/concern (19\%) and depression (17\%), and with respect to their skin symptoms, patients most often chose embarrassment (24\%), fatigue $(23 \%)$, worry/concern (14\%) and depression (12\%). When asked to rate the impact of their disease in certain scenarios or situations, more than $25 \%$ of patients reported that their joint symptoms had a severe impact (a choice of 8,9 or 10 on a 10 -point scale with $0=$ no impact and $10=$ severe) on fatigue $(32 \%)$ "leisure activities" $(26 \%)$, "how they think of themselves" $(25 \%)$ and "how others felt about them" (26\%). More than $25 \%$ of patients reported that their skin symptoms had a severe impact on fatigue (28\%) "how they think of themselves" $(27 \%)$,"how others thought of them" (27\%) and "making a first impression" (28\%).
Conclusions: In this survey of patients with PsA, we evaluated the patient's perspective on the burden of both skin-related and joint-related symptoms with the PSAQoL and WPAI as well as with a set of novel questions. Both skin and joint symptoms have a broad and meaningful impact on patient QoL, work productivity and patients reported a range of emotions as well as a variety of impacts on their daily activities with respect to skin and joint symptoms. This data highlights that there is a unique impact of PsA for each patient.

Disclosure of Interest: J. Merola Grant/research support from: Amgen; Biogen Idec, Boehringer Ingelheim, Pfizer, Consultant for: Abbvie, Amgen, Biogen Idec Celgene, Eli Lilly and Company, GlaxoSmithKline, Janssen, Kiniksa Pharmaceuticals, Mallingkrodt, Merck, Momenta, Novartis, Pfizer, Samumed, Sanofi, Science37, and UCB, D. Shrom Shareholder of: Eli Lilly and Co, Employee of: El Lilly and Co, J. Eaton Shareholder of: Eli Lilly and Co, Employee of: Eli Lilly and Co, C. Dworkin: None declared, C. Kresbach: None declared, B. Shah-Manek: None declared, J. Birt Shareholder of: Eli Lilly and Co, Employee of: Eli Lilly and Co

DOI: 10.1136/annrheumdis-2018-eular.3458

\section{AB0930 REAL-WORLD EFFECTIVENESS AND SAFETY OF APREMILAST IN GERMAN PATIENTS WITH PSORIATIC ARTHRITIS: ANALYSIS OF AN ONGOING MULTICENTRE, PROSPECTIVE, NON-INTERVENTIONAL STUDY}

J. Wollenhaupt ${ }^{1}$, T. Klopsch ${ }^{2}$, H. Strothmeyer ${ }^{3}$, S. Morys ${ }^{4}$, C. Bach ${ }^{4}$, N. Nunez Gomez ${ }^{4}{ }^{1}$ Schoen Klinik Hamburg Eilbek, Klinik für Rheumatologie, Hamburg; ${ }^{2}$ Praxis Dr. med. Thilo Klopsch, Neubrandenburg; ${ }^{3}$ Rheumatologische Gemeinschaftspraxis Düsseldorf, Düsseldorf, ${ }^{4}$ Celgene $\mathrm{GmbH}$, München, Germany

Background: Apremilast (APR) has been studied extensively in phase III randomised, controlled trials. However, there is a lack of real-world evidence of effectiveness and safety in a broad population of pts with psoriatic arthritis (PsA)

Objectives: To assess effectiveness and safety of APR in pts with active PsA from routine clinical practice settings in Germany.

Methods: In this multicentre, prospective, non-interventional study, the primary endpoint was the proportion of pts reaching $>1$ point $(>20 \%)$ improvement from baseline (BL) in the Physician's Global Assessment of Disease Activity (PhGA) score. Other endpoints included effects on tender and swollen joint counts, psoriasis-affected body surface area (BSA), enthesitis, dactylitis, Patient's Global Assessment of Disease Activity score (PtGA), Psoriatic Arthritis Impact of Disease tool (PsAID), pain and pruritus. The current analysis is based on observed data. Results: The first 202 of a planned 500 German pts receiving APR for $>4$ month ( $>1$ month [V1], $>4$ month [V2]) and 127 pts receiving APR for $\geq 7$ months (V3) were evaluated. Mean age was 54 years, mean BMI was $29 \mathrm{~kg} / \mathrm{m}^{2}$ and $61 \%$ were female. The mean duration of psoriasis was 25 years and of PsA was 18 years; $\approx 30 \%$ of pts were biologic-experienced. The mean (SD) PhGA was $2.5(0.56)$ at BL. After V1, 60\% of pts achieved $>1$ point improvement in PhGA, which increased to $76 \%$ (V2) and $87 \%$ (V3). Mean (SD) PhGA decreased to 1.7 (0.69), $1.4(0.73)$ and $1.1(0.74)$ at V1, V2, and V3 respectively. Achievement of a PhGA of $0-1$ increased from $0 \%$ of pts at BL to $36.8 \%(\mathrm{~V} 1), 65.0 \%$ (V2) and $77.2 \%(\mathrm{~V} 3)$ Median improvements in tender and swollen joint counts from BL to V3 were $57.1 \%$ and $60.0 \%$, respectively. BSA improved from $11.4 \%$ at BL to $8.3 \%, 5.1 \%$ and $3.5 \%$ at $\mathrm{V} 1, \mathrm{~V} 2$ and $\mathrm{V} 3$, respectively. At BL, $48.4 \%$ of pts had enthesitis based on Leeds Enthesitis Index; $46 \%$ reached a score of 0 by V1, $57 \%$ by V2\% and $60 \%$ by V3. At BL, $27.3 \%$ of pts had dactylitis; a score of 0 was achieved by $40.0 \%, 66.7 \%$ and $71.9 \%$ of pts by $\mathrm{V} 1, \mathrm{~V} 2$, and $\mathrm{V} 3$, respectively. BL mean PsAID score (5.33; $\max =10.00$ ) decreased to 4.40 (V1), 3.85 (V2) and 3.36 (V3) Improvements were also seen in PtGA, overall pain and pruritus. A sub-analysis suggests that APR was associated with greater benefits in biologic-naive pts compared with pts who previously received biologic therapies. The observed safety and tolerability after $\mathrm{V} 3$ was consistent with the known overall safety profile of APR. Common AEs in clinical trials were similar, with a lower incidence: diarrhoea $(10.4 \%)$, nausea $(5.6 \%)$, headache $(4.0 \%)$, and respiratory tract infection $(1.2 \%)$. Conclusions: The first results from this real-world PsA study reinforce findings from previous clinical trials of APR. In pts with $>4$ and $>7$ months of follow-up, APR was associated with improvements in both physician-assessed and patientreported outcomes, with possibly a greater benefit in biologic-naïve compared with biologic-experienced pts. Safety and tolerability were similar to the known profile of APR.

Disclosure of Interest: J. Wollenhaupt Grant/research support from: Celgene Corporation, T. Klopsch: None declared, H. Strothmeyer: None declared, S Morys Employee of: Celgene GmbH, C. Bach Employee of: Celgene GmbH, N. Nunez-Gomez Employee of: Celgene GmbH DOI: 10.1136/annrheumdis-2018-eular.5431 


\section{AB0931 PERSISTENCE WITH SUBCUTANEOUSLY ADMINISTERED BIOLOGICS AMONG PATIENTS WITH PSORIATIC ARTHRITIS: ANALYSES FROM A US CLAIMS DATABASE}

K. Oelke ${ }^{1}$, O. Chambenoit ${ }^{2}$, A. Majhoo ${ }^{3}$, S. Gray ${ }^{4}$, K. Higgins ${ }^{4}$, P. Hur ${ }^{2}$.

${ }^{1}$ Rheumatic Disease Center, Glendale, Wl; ${ }^{2}$ Novartis Pharmaceuticals Corporation, East Hanover, $\mathrm{NJ} ;{ }^{3}$ Shores Rheumatology, St. Clair Shores, Ml; ${ }^{4}$ Truven Health Analytics, an IBM Company, Cambridge, MA, USA

Background: Persistence with biologic therapies among patients with psoriatic arthritis (PsA) provides insight into the real-world effectiveness of biologics in routine clinical practice. With different dosing schedules and durations of action of currently available biologics, measuring persistence using varying treatment gap cutoffs may better guide physicians in their treatment decisions.

Objectives: To evaluate the persistence of subcutaneously (SC) administered biologics in patients with PsA.

Methods: Patients with $\geq 1$ pharmacy claim for an FDA-approved SC biologic (adalimumab, certolizumab pegol, etanercept, golimumab, and secukinumab) for the treatment of PsA between 01/15/2016 and 07/31/2017 were identified in the Truven Health Analytics MarketScan Commercial and Medicare Supplemental Databases. Eligible patients were aged $\geq 18$ years at the time of biologic initiation (index date) and continuously enrolled with medical and pharmacy claims $\geq 12$ months prior to (baseline period) and $\geq 12$ months after the index date. Patients had $\geq 1$ PsA diagnosis (ICD-9-CM 696.0 or ICD-10-CM L40.5x) and no pharmacy claims for the index biologic during the baseline period. Persistence over 12 months was measured as the discontinuation rate and number of days persistent on the biologic therapy from the index date to reported treatment gaps of $\geq 45, \geq 90$, and $\geq 180$ days based on clinical expert opinion, or the end of follow-up if no gap was observed. The median time to discontinuation of the index biologic over 12 months was assessed by Kaplan-Meier analysis for each treatment gap cutoff.

Results: A total of 1558 patients with PsA enrolled in the analysis initiated SC biologics, including adalimumab $(n=720)$, certolizumab pegol $(n=93)$, etanercept $(n=426)$, golimumab $(n=64)$, and secukinumab $(n=255)$. Overall, 680 patients (43.6\%) discontinued their index biologic therapy during 12 month follow-up. The 12 month discontinuation rate for each treatment gap cutoff was lowest with secukinumab compared with other SC biologics $(51.8 \%, 36.5 \%$, and $21.6 \%$ for patients with treatment gaps $\geq 45$ days, $\geq 90$ days, and $\geq 180$ days, respectively). Mean days persistent on the index biologic was the highest with secukinumab for each treatment gap cutoff ( 254.5 days, 282.8 days, and 307.5 days for patients with treatment gaps $\geq 45$ days, $\geq 90$ days, and $\geq 180$ days, respectively) and the lowest with certolizumab pegol ( 218.1 days and 240.7 days for patients with treatment gaps $\geq 45$ days and $\geq 90$ days, respectively) and etanercept (270.7 days for patients with a treatment gap $\geq 180$ days; table 1$)$. The median $(95 \% \mathrm{Cl})$ time to discontinuation for patients with a treatment gap $\geq 45$ days was the highest with secukinumab (308 [238 to >365] days) and lowest with certolizumab pegol (216 [155 to 274] days). Median time to discontinuation could not be calculated for patients with treatment gaps $\geq 90$ days or $\geq 180$ days due to low event rates and limited follow-up.

Abstract AB0931 - Table 1. Persistence With Index Biologic Therapies Over 12 Months of Follow-Up in Patients With Psoriatic Arthritis $(\mathrm{N}=1558)$

\begin{tabular}{|l|c|c|c|c|c|}
\hline & $\begin{array}{c}\text { Adallimumab } \\
(\mathbf{n}=720)\end{array}$ & $\begin{array}{c}\text { Certolizumab } \\
\mathbf{P e g o l} \\
(\mathbf{n}=93)\end{array}$ & $\begin{array}{c}\text { Etanercept } \\
(\mathbf{n}=426)\end{array}$ & $\begin{array}{c}\text { Golimumab } \\
(\mathbf{n}=64)\end{array}$ & $\begin{array}{c}\text { Secukinumab } \\
(\mathbf{n}=\mathbf{2 5 5})\end{array}$ \\
\hline Discontlnuation of Index drug, $\mathbf{n}(\%)$ & & & & & \\
\hline Treatment gap $\geq 45$ days & $395(54.9)$ & $61(65.6)$ & $255(59.9)$ & $38(59.4)$ & $132(51.8)$ \\
\hline Treatment gap $\geq 90$ days & $307(42.6)$ & $48(51.6)$ & $203(47.7)$ & $29(45.3)$ & $93(36.5)$ \\
\hline Treatment gap $\geq 180$ days & $208(28.9)$ & $32(34.4)$ & $148(34.7)$ & $21(32.8)$ & $55(21.6)$ \\
\hline $\begin{array}{l}\text { Days persistent on index drug, mean } \\
(\text { SD) }\end{array}$ & & & & & \\
\hline Prior to gap of $\geq 45$ days & $253.2(120.5)$ & $218.1(127.1)$ & $236.5(125.8)$ & $233.5(128.4)$ & $254.5(123.8)$ \\
\hline Prior to gap of $\geq 90$ days & $266.0(123.8)$ & $240.7(131.9)$ & $249.5(130.4)$ & $253.7(132.4)$ & $282.8(117.5)$ \\
\hline Prior to gap of $\geq 180$ days & $288.7(122.7)$ & $272.1(131.8)$ & $270.7(132.5)$ & $273.0(135.7)$ & $307.5(112.2)$ \\
\hline
\end{tabular}

$<$ ??>Days persistent (ie, time to discontinuation) was defined as the time from the index prescription fill to the last day the drug was on hand to give a gap of $\geq 45,90$, or 180 days without the index drug, or the end of follow-up if no gap was observed. Conclusions: Patients who initiated secukinumab showed higher persistence over 12 months of follow-up compared with the other SC biologics assessed, regardless of the treatment gap.

Acknowledgements: This study was sponsored by Novartis Pharmaceuticals Corporation, East Hanover, NJ.

Disclosure of Interest: K. Oelke Consultant for: Novartis Pharmaceuticals Corporation, Speakers bureau: AbbVie, Amgen, Bristol-Meyers Squibb and Pfizer, O. Chambenoit Employee of: Novartis Pharmaceuticals Corporation, A. Majjhoo Grant/research support from: Novartis Pharmaceuticals Corporation, Consultant for: Novartis Pharmaceuticals Corporation, Speakers bureau: Novartis Pharmaceuticals Corporation, S. Grey Employee of: Truven Health Analytics, an IBM
Company, K. Higgins Employee of: Truven Health Analytics, an IBM Company, P Hur Employee of: Novartis Pharmaceuticals Corporation

DOI: 10.1136/annrheumdis-2018-eular.1593

\section{AB0932 HELICOBACTER PYLORI ANTIGEN SPECIFIC ANTIBODIES IN PSORIATIC ARTHRITIS}

E. Patrikiou ${ }^{1}$, C. Liaskos ${ }^{1}$, E. Zafiriou ${ }^{2}$, G. Efthymiou ${ }^{1}$, T. Scheper ${ }^{3}$, W. Meyer ${ }^{3}$, A. Roussaki-Schulze ${ }^{2}$, L.I. Sakkas ${ }^{1,1}$, D.P. Bogdanos ${ }^{1} .{ }^{1}$ Rheumatology and Clinical Immunology, ${ }^{2}$ Dermatology, Faculty of Medicine, School of Health Sciences, University of Thessaly, Larissa, Greece; ${ }^{3}$ Institute of Immunology, EUROIMMUN, Lübeck, Germany

Background: The role of Helicobacter pylori $(\mathrm{Hp})$ infection in the aetiopathogenesis of psoriatic arthritis (PsA) and psoriasis (Ps) is currently inconclusive, as studies reported increased, decreased or comparable to controls frequency of anti-Hp antibodies.

Objectives: To test antigen-specific $\mathrm{Hp}$ antibodies in a well-defined cohort of PsA patients and demographically matched Ps patients and healthy controls (HCs). Methods: A total of 140 serum samples (48 PsA, 37 Ps and $55 \mathrm{HCs}$ ) were tested for anti-Hp antibodies by a western blot immunoassay using whole $\mathrm{Hp}$ extract as antigenic source.

Results: Overall, anti-Hp seropositivity was similar in PsA (19/48, 39.6\%) and Ps $(16 / 3743.2 \%, p>0.05)$ but significantly lower compared to HCs $(33 / 55,60 \%$, PsA vs $\mathrm{HC}, \mathrm{p}=0.039)$. Overall, $\lg \mathrm{G}$ anti-CagA and $\mathrm{VacA}$, the most diagnostically relevant anti-Hp antibodies, were present in $26 / 48(54.2 \%)$ and $5 / 48(10.4 \% \%)$ PsA patients, respectively, compared to $15 / 37(40.5 \%)(p=n s)$ and $1 / 37(2.7 \%)(p=n s)$ Ps respectively, as well as in 39/55 (70.9\%), ( $p=0.079)$ and 4/55/97.2\%) ( $p=n s)$ $\mathrm{HCs}$, respectively. Compared to $\mathrm{HCs}$, patients with $\mathrm{PsA}$ had higher reactivity to p29 (UreA) $(31 / 48,64.6 \%$ vs $24 / 55,43.5 \%, p=0.033)$ and to p54 $(24 / 48,50 \%$ vs $15 / 55,27.2 \%, p=0.017$ ) and tended to have higher positivity against p75 antigen $(9 / 48,18.9 \%$ vs $3 / 55,5.4 \%, p=0.062)$. Reactivity to $p 50(15 / 48,31.3 \%$ vs 50.9 , $p=0.042)$ and $p 33$ antigen $(3 / 48,6.3 \%$ vs $10 / 55,18.2 \%, p=0.061)$ was lower in PsA than in HCs. No differences on anti-Hp antigen specific antibodies was found between PsA and Ps

Conclusions: Although overall reactivity to $\mathrm{Hp}$ in PsA and $\mathrm{Ps}$ is lower than $\mathrm{HCs}$, $\mathrm{Hp}$ infection cannot safely be considered a protecting microbial agent for these diseases, as reactivities to some $\mathrm{Hp}$ antigens are more frequently recognised to these diseases than in $\mathrm{HCs}$.

Disclosure of Interest: E. Patrikiou: None declared, C. Liaskos: None declared, E. Zafiriou: None declared, G. Efthymiou: None declared, T. Scheper Employee of: EUROIMMUN, W. Meyer Employee of: EUROIMMUN, A. Roussaki-Schulze: None declared, L. Sakkas: None declared, D. Bogdanos: None declared DOI: 10.1136/annrheumdis-2018-eular.6716

\section{AB0933 SURVIVAL AT 6 AND 12 MONTHS OF USTEKINUMAB IN PATIENTS WITH PSORIATIC ARTHRITIS IN CONDITIONS OF CLINICAL PRACTICE}

L. Perez Albaladejo, I. Notario Ferreira, I. Añón Oñate, M. Á. Ferrer González, M. J. Soto Pino, S. Quirosa Flores, A. García Sánchez, M.C. Ramírez Barberena, M. Ramírez de la Torre, J.M. Andreu Ubero, R. Cáliz Cáliz. HOSPITAL UNIVERSITARIO VIRGEN DE LAS NIEVES, Granada, Spain

Introduction: Psoriatic arthritis (PsA) is a chronic inflammatory disease associated with skin psoriasis. Ustekinumab is a monoclonal antibody which inhibits IL12/23 and has proven efficacy and safety in the treatment of patients with PsA.

Objectives: To determine the survival rate and the reasons for Ustekinumab discontinuation in a patient cohort with PsA in conditions of clinical practice.

Methods: Descriptive, prospective, longitudinal and open study including 66 patients diagnosed with PsA and treated with Ustekinumab at dosis according to the data sheet (45 mg in the 0,4 and every 12 weeks), except for 3 patients who were administered a $90 \mathrm{mg}$ dose with the aforementioned regimen. The patients were monitored at 6 and 12 months. The following variables were collected: age, sex, years of evolution, previous treatment with Synthetic Disease Modifying AntiRheumatic Drugs (DMARDs) and/or biologic DMARD. All the adverse events $(A E)$ which caused the discontinuation of the drug in patients who had received at least one dose of Ustekinumab were also collected. The Kaplan-Meier method was used to analyse the survival rate. The survival rate in naïve patients with biologic DMARD was compared with those who had received at least one biologic DMARD treatment before; and patients treated with Ustekinumab in monotherapy with those who were in a combined therapy with DMARDs. The Log-Rank Test was used for the comparative analysis of both subgroups

Results: Out of the 66 patients of our cohort, 34 (51.5\%) were women, whose mean age was $47.2 \pm 11.3$ years. 49 presented only peripheral affectation $(74.2 \%)$ mainly in polyarticular form, and 10 had mixed affectation. The rest presented axial affectation exclusively. Our patients had been suffering from this disease for 
an average of $6 \pm 7.7$ years, and had received an average of $1.26 \pm 1.45$ previous biologic DMARD. $51.5 \%$ were receiving Ustekinumab in a combined therapy with DMARD (most of them Methotrexate) and $48.5 \%$ were in monotherapy. The survival rates at 6 and 12 months were $85 \%$ and $74.6 \%$ respectively. Comparing the subgroups, the naïve patients with biologic DMARDs presented higher survival rates at $6(91.6 \%$ vs $80.7 \%)$ and at 12 months ( $85.1 \%$ vs $66.7 \%)$, a statistically significant difference with the group that received previous biologic DMARD $(p=0.036)$. The patients in combined therapy with DMARDs presented higher rates of survival than the patients in monotherapy with Ustekinumab ( $90 \%$ vs $80 \% ; 78 \%$ vs $71.1 \%$ at 6 and 12 months respectively), although the differences were not statistically significant. The main reason for discontinuation was the decrease of efficacy (14 patients; $21.2 \%$ ), mostly in patients who had received previous treatment with biologic DMARD. 5 patients $(7.6 \%)$ did not continue due to $\mathrm{AE}$ (2 due to relapsing herpes zoster; 1 patient deceased, with a personal history of neoplasms and a previous treatment with anti-TNF; and 2 had reactions at the injection site)

Conclusions: Ustekinumab is a safe drug, presenting high rates of drug retention, especially in patients who have not received any previous biologic therapy.

Disclosure of Interest: None declared

DOI: 10.1136/annrheumdis-2018-eular.3900

\section{\begin{tabular}{l|l}
\hline AB0934 & OBESITY IN PATIENTS WITH PSORIATIC ARTHRITIS IN \\
OUR AREA
\end{tabular}}

L. Montolio-Chiva ${ }^{1}$, M. Robustillo-Villarino ${ }^{1}$, A. Sendra-Garcia ${ }^{2}$, A. Martínez-Ferrer ${ }^{1}$ C. Vergara-Dangond ${ }^{1}$, M. Aguilar-Zamora ${ }^{1}$, A.V. Orenes-Vera ${ }^{1}$, E. Valls-Pascual ${ }^{1}$, D. Ybáñez-García ${ }^{1}$, V. Núñez-Monje ${ }^{2}$, I. Torner-Hernández ${ }^{1}$, J.J. Alegre-Sancho' ${ }^{1}$. ${ }^{1}$ Rheumatology, Hospital Dr Peset, ${ }^{2}$ Rheumatology, Foundation for the Promotion of Health and Biomedical Research of Valencia (FISABIO), Valencia, Spain

Background: Obesity is a comorbid condition in patients with psoriasis which tends to be less common in patients with psoriatic arthritis (PsA). In the general population, obesity is associated with increased inflammatory load and vascular risk, and with hypovitaminosis $\mathrm{D}$.

Objectives: To explore the relationship between obesity and disease activity, vascular damage, serum concentrations of vitamin $\mathrm{D}(25 \mathrm{OHD})$ and bone mineral density (BMD) in patients with PsA.

Methods: Descriptive cross-sectional study. Patients with PsA patients and peripheral joint involvement were consecutively included. Demographic (age, sex), clinical [duration of the disease, BMI (body mass index), DAS28] and analytical (25OHD, CRP, ESR) variables were collected. Patients with a BMI $\geq 30 \mathrm{~kg} / \mathrm{m}^{2}$; were considered obese, and we considered vitamin $\mathrm{D}$ deficiency when $250 \mathrm{HD}<20 \mathrm{ng} / \mathrm{ml}$ and vitamin D insufficiency when $250 \mathrm{HD} 20-30 \mathrm{ng} / \mathrm{ml}$. Within a period of 3 months, atheroma plaque and intima media thickness (IMT) measurement was performed by ultrasonography of the carotid arterial tree using an Esaote MyLab70XVG with a 7-12 MHz linear transducer and an automated program measuring IMT through radiofrequency (Quality intima media Thickness in real time, QIMT). Pulse wave velocity (PWV) was obtained by analysis of brachial pulse waves with an automated and validated system (Mobil O Graph). IMT>900 $\mu$ and $\mathrm{PWV} \geq 10 \mathrm{~m} / \mathrm{s}$ were considered pathological. Measurement of BMD was performed using an HOLOGIC densitometer. Statistical analysis was performed with the SPSS 17.0 program.

Results: We included 108 patients, $60 \%$ women, with a meanage of 55,6 (SD $12,6)$ years and a mean duration of PsA of 19,5 (SD 28) years. The mean BMI was $27(\mathrm{DE} 5,4) \mathrm{kg} / \mathrm{m}^{2}$;, $35 \%$ of the patients being obese. The mean CRP, ESR and DAS28 were 6,6 (DE 4,5) mg/l, 10,7(DE 11) mm/h and 2,32(DE 0,8), respectively. $28 \%$ of patients had $250 \mathrm{HD}$ deficiency and $32 \%$ had $25 \mathrm{OHD}$ insufficiency. The mean values of the IMT and PWV were 715 (SD 149) $\mu$ and PWV 8 (SD 1.8) $\mathrm{m} / \mathrm{s}$, respectively. $12 \%$ of patients had osteoporosis, and up to $39 \%$ had osteopenia. Obesity was associated with a higher PsA activity measured by CRP ( 8.5 vs $5.7 \mathrm{mg} / \mathrm{L}, \mathrm{p}=0.001$ ) and ESR (38.6 vs $8.7 \mathrm{~mm} / \mathrm{h}, \mathrm{p}=0,04)$, although DAS28 was not different between groups. We also observed differences between obese and non-obese regarding the mean values of IMT (770 vs $709 \mu, \mathrm{p}=0.046)$ and PWV ( $8.9 \mathrm{vs} 8 \mathrm{~m} / \mathrm{s}, \mathrm{p}=0.021$ ), the presence of atheroma plaque nearly reaching statistical significance $(39 \%$ vs $30 \%, p=0,07)$. No association was observed between obesity and 25OHD levels, BMD and DAS28.

Conclusions: obesity is linked to an increased inflammatory load and more vascular damage in our PsA patients. A strategy of tight control of obesity and other vascular risk factors should be implemented when monitoring PsA patients.

Disclosure of Interest: None declared

DOI: 10.1136/annrheumdis-2018-eular.7364

\section{AB0935 \\ CANADIAN ADALIMUMAB POST-MARKETING OBSERVATIONAL EPIDEMIOLOGICAL STUDY ASSESSING THE EFFECTIVENESS OF ADALIMUMAB VS NON-BIOLOGIC DMARDS IN PSORIATIC ARTHRITIS (COMPLETE-PSA): 12-MONTH EFFECTIVENESS DATA}

M. Khraishi ${ }^{1}$, L. Bessette ${ }^{2}$, A. Chow ${ }^{3}$, B. Haraoui ${ }^{4}$, V. Pavlova ${ }^{5}$, J. Stewart ${ }^{6}$ V. Remple ${ }^{7} .{ }^{1}$ Memorial University of Newfoundland, St. John's; ${ }^{2}$ Laval University Centre Hospitalier de I'Université Laval, Quebec; ${ }^{3}$ University of Toronto, Toronto; ${ }^{4}$ Centre Hhospitalier de l'Université de Montréal, Montreal; ${ }^{5}$ McMaster University, Hamilton; ${ }^{6}$ University of British Columbia, Penticton; ${ }^{7}$ AbbVie Corporation, Montreal, Canada

Background: To date, observational studies comparing the effectiveness of adalimumab (ADA) to non-biologic DMARDs (nbDMARD) in psoriatic arthritis (PsA) patients failing prior treatment are scarce. COMPLETE-PSA is a Canadian postmarketing observational study which assessed real-life effectiveness of ADA and non-biological therapies (NSAIDs and DMARDs) in PSA management following initial treatment failure.

Objectives: This analysis aimed to describe the baseline demographic and dis ease parameters of patients initiating nbDMARD or ADA and compare the 12 month real-life effectiveness of both treatments.

Methods: Patients eligible for COMPLETE PsA are anti-TNF $\alpha$ naïve adults, with active PsA who require change in their treatment regimen, per the judgment of the treating physician. In the current analysis patients enrolled during Jul/2011-Jun/ 2016 were included. Outcome measures analysed were: DAS28, SF-12, DLQI, presence of extra-articular manifestations (EAMs; enthesitis and dactylitis), psoriasis BSA, achievement of modified MDA (defined as achievement of [i] 4 of 6 (MDA 1) and [ii] 5 of the following 6 criteria (MDA 2): TJC $\leq 1$, SJC $\leq 1, B S A \leq 3 \%$, pain VAS $\leq 15 \mathrm{~mm}, \mathrm{PtGA} \leq 20$ and $\mathrm{HAQ} \leq 0.5$ ), modified remission (defined as $\mathrm{SJC}=0, \mathrm{TJC}=0$, absence of enthesitis and dactylitis, BSA $\leq 3 \%$ and $\mathrm{HAQ} \leq 0.5$ ), DAPSA LDA $(\leq 14)$, and DAPSA remission (REM; $\leq 4)$. Analyses were conducted by initial group assignment (intent-to-treat approach).

Results: 406 patients were included (nbDMARD $n=146$, ADA $n=260$ ). Baseline demographics were comparable between treatment groups. However, patients initiating ADA were more likely to be unemployed (47.3\% ADA vs $34.9 \%$ nbDMARD, $\mathrm{p}=0.015)$, had higher DAS28 (4.8 vs 4.4, $\mathrm{p}=0.002)$ and total DLQI score (6.1 vs $4.3, p=0.007)$, and were more likely to have $B S A \geq 3 \%(44.6 \%$ vs $35.0 \%, p=0.063)$ and high DAPSA disease activity $(50.8 \%$ vs $32.3 \%, p=0.015)$. A higher proportion of nbDMARD patients had dactylitis $(36.1 \%$ vs $25.3 \%, p=0.023)$. No differences were observed between groups in enthesitis, overall EAMs, or QoL at baseline.

Upon 12 months of treatment, mean adjusted DAS28 (2.6 vs $3.4, p<0.001$ ) and DLQI (2.2 vs 2.9, $\mathrm{p}=0.530$ ) scores, but not SF-12, were lower in the ADA group. Furthermore, although statistical significance was not always met, patients treated with ADA had lower DAPSA score $(\mathrm{p}=0.025)$ (LDA/REM: $64.9 \%$ vs $58.6 \%$; REM: $37.7 \%$ vs $17.1 \%$ ), were more likely to be in modified remission $(14.7 \%$ vs $9.7 \%$, $\mathrm{p}=0.311$ ), and to have mMDA (mMDA 1: $15.6 \%$ vs $12.6 \%, p=0.529$; mMDA 2 $17 \%$ vs $11.5 \%, p=0.253)$ and $B S A<3 \%(89.3 \%$ vs $83.9 \%, p=0.207)$. Also, EAM prevalence decreased in both groups but was significantly lower in the ADA group (17.4\% vs $35.8 \%, \mathrm{p}<0.001)$

Over time, $9.6 \%$ of ADA patients initiated another biologic and $32.2 \%$ of patients in the nbDMARD group initiated biologic treatment $(p<0.001)$

Conclusions: PsA patients initiating ADA in Canadian routine clinical care have significantly greater baseline disease severity compared with those initiating nbDMARDs. However, 12 month ADA treatment improved disease control and EAMs. DAPSA-REM evaluation seems more sensitive than mMDA in differentiating both populations.

Acknowledgements: JSS Medical Research, Montreal, Canada

Disclosure of Interest: M. Khraishi Consultant for: AbbVie, Speakers bureau: AbbVie, L. Bessette Consultant for: Amgen, BMS, Janssen, Roche, UCB, AbbVie, Pfizer, Celgene, Lilly, Novartis, Speakers bureau: Amgen, BMS, Janssen, Roche, UCB, AbbVie, Pfizer, Merck, Celgene, Lilly, Novartis, A. Chow Consultant for: AbbVie, Amgen, BMS, Celgene, Janssen, Lilly, Merck, Novartis, Pfizer, Roche Speakers bureau: AbbVie, BMS, Janssen, Pfizer, Takeda, B. Haraoui Grant/ research support from: AbbVie, Amgen, BMS, Janssen, Pfizer, Roche, and UCB Consultant for: AbbVie, Amgen, BMS, Celgene, Eli Lilly, Janssen, Merck, Pfizer, Roche, and UCB, Speakers bureau: Amgen, BMS, Janssen, Pfizer, and UCB, V. Pavlova Consultant for: Amgen, Abbvie, BMS, Janssen, Lilly, Merk, Novartis, Roche, UCB, Pfizer, Speakers bureau: Amgen, Abbvie, BMS, Janssen, Lilly, Merk, Novartis, Roche, UCB, Pfizer, J. Stewart Consultant for: Pfizer, Abbvie Amgen, Celgene, Roche, Novartis, V. Remple Shareholder of: AbbVie, Employee of: AbbVie

DOI: 10.1136/annrheumdis-2018-eular.3787 